\title{
Evaluating students' perceptions of a scenario-situated business communication course
}

\section{Siriol Lewis}

University of Glasgow, UK

\section{Abstract}

Research has identified that Business students, who are immersed in theoretical concepts, may not be equipped with the skills required to operate successfully in the global workplace in the English medium (Evans, 2013). Secondly, tasks in Business English textbooks tend not to bear much resemblance to those of a work environment (Bremner, 2010; Evans, 2013). This paper discusses an optional written business communication course open to international postgraduate Business School students. Although the course is worth ten credits, it can only be used for a separate award, not part of their degree programme. The course focuses on the use of appropriate register, Business English vocabulary and intertextuality, as these features have been identified as pivotal to successful written business communication (Evans, 2013). A short questionnaire was distributed to the students towards the end of course to elicit their perceptions of the usefulness of the course. Consisting of two closed questions and one open question, data was then coded using constructivist grounded theory (Mills, Birks and Hoare, 2014), from which themes emerged providing valuable and unexpected feedback. The primary finding was that the course appeared to have alerted students to the importance of the business writing genre, resulting in an overwhelming request for more instruction.

Keywords: written business communication; intertextuality; grounded theory.

\section{Introduction}

This paper reviews an innovative optional written business communication course open to international postgraduate students at the Adam Smith Business School, University of Glasgow. Following a request from faculty, a business communication course focusing on speaking skills was established. It quickly became apparent that there was an additional 
demand for a written business communication course. Needs analysis showed that report writing, formal letters and related employment texts such as curriculum vitae, were identified as areas where students would like assistance. Conventions of style and genre were also identified as problematic.

Successful completion of the course contributes to the University's Graduate Award, which seeks to close the gap between academia and employability. However, previous research on Business textbooks has revealed a disparity between content and real-life business environments. Tasks in Business English textbooks are often typical English as a Foreign Language exercises, which do not reflect genuine business activities (Reed, 2011). An additional observation was that the materials typically included in Business English publications were based on a priori assumptions rather any rigorous investigation (St John, 1996). Other researchers also highlighted the lack of connection between materials and actual tasks in the business environment (Bremner, 2010; Cheng and Cheng, 2010). In his Hong Kong study, Evans (2013) found emails and reports dominated workplace communication, recommending that course designers incorporate such features as unpredictability, problem solving, intertextuality, collaboration and precision in writing. For this to be actualised, the course should be based on simulated and clearly defined role play to facilitate more authentic responses to tasks. Hence, this ten-week course is centred around a scenario.

Students act as interns at a communications company for the first five weeks of the course, and then move to an 'assessment centre' for the remaining five weeks. Tasks were designed around publicly available information from a telecommunications conglomerate, supplemented by related purposely written non-authentic material. Using a task-based learning framework, activities primarily focused on maintaining customer relationships, and writing internal written communications, necessitating register switch and a high degree of intertextuality, which has been identified as crucial to business communication (Evans, 2013).

Intertextuality can pose a challenge for students (Bremner and Costley, 2018). In particular, the dialogic nature of intertextuality and the amount of assumed and shared knowledge appear problematic. A classroom cannot replicate a workplace and the complex internal relationship structure. Bremner (2010) commented that workplace intertextuality can be a positive influence, providing formats and guidelines. Students 
rarely have access to other connected texts, for example an email chain, reports, press releases and other corporate material. To address this, relevant texts were provided in the course book. However, Bremner (2010) also noted that prolific intertextuality can be quite restrictive, and it may be that students feel constrained by the requirement to reuse terminology and collocations. Indeed, intertextuality highlighted another unforeseen issue. Students were quite anxious about plagiarism due to the necessity to reuse collocations and specific vocabulary from the supplied texts. This reinforced the idea that intertextuality and corporate language are very distinct and necessary features of the genre.

\section{The Course}

The course outcomes state that students will be able to demonstrate knowledge and effective use of genre, structure, business vocabulary and register, and to demonstrate intertextual relationships. Explicitly, in the first semester the focus is on email and letter writing to different audiences, necessitating register switch. In semester two, the focus is job applications, specifically layout and organisation, sentence-level writing and grammar. Opportunities for group work were encouraged, although most writing tasks were individual. Assessed individual letter-writing tasks were administered in weeks five and ten, weighted at $40 \%$ and $60 \%$ respectively. The classes took the form of one two-hour session per week, with the expectation that students would complete tasks out of class and submit texts on a weekly basis via the Virtual Learning Environment. Peer feedback was followed by comparison with an exemplar text. The emphasis was very much on students working independently and in groups.

Exemplars of texts included highlighted features of Business English and recycled English from provided texts, thereby encouraging intertextuality, use of synonyms and examples of language of persuasion and inclusion. Comparison of students' work and the exemplar tasks provided opportunities for 'noticing' (Qi and Lapkin, 2001) and facilitated student enquiry concerning synonyms, collocations, and finer semantic distinctions.

Students were asked to produce ten texts including collaborative reports, internal emails, personal statements, short answer responses, and letters. The first task involved writing an adjustment letter to a dissatisfied customer. Relying heavily on supplied texts such as the Chairman's statement, and non-authentic emails, students were encouraged to 
promote the company's declared values, placate and retain the customer, and personalise the response. This proved quite challenging. Flowerdew (2010) found in her study that students acknowledged the need to be persuasive but were unsure how to achieve this in writing. To aid the noticing process, tables were included, consisting of questions to evaluate students' texts in peer feedback, for example:

Q 4- to what extent do the writer and audience share the same knowledge?

Q 11- what politeness markers/hedges are used?

$Q$ 12- [whether the text] achieves suitable tone by using, for example, variety of minimizing adverbs, attitudinal markers, 'self' references?

(Advancing English for Business Writing Course book, 2018-2019, pp.95-96).

In week four, the students formed groups and collaboratively wrote a report. Workplace roles are usually quite clearly delineated, in contrast to the classroom where the students are on an equal standing. This requires soft skills of teamwork, adaptability, possible conflict resolution and leadership. Each group received peer feedback on this report and on a later report. On this second occasion, they wrote reflectively on their experiences of collaboration.

In week six, the scenario 'moved' from internship to assessment centres. Students were required to choose a job from a selection of supplied advertisements, and prepare a personal statement, a curriculum vitae and short answer responses. They were directed to the university's online careers service and encouraged to make appointments with careers advisers for individual curriculum vitae (CV) writing assistance. Feedback was given by peers, and in contrast to the first half of the course, exemplars were not distributed.

\section{Methodology}

The questionnaire consisted of two questions on a Likert scale, and one open question. The first two questions were constructed to elicit students' opinions as to whether the course had increased their confidence in business written communication in English and in applying for employment requiring the use of English. 227 international postgraduate Business students originally enrolled in the course. Degree courses ranged from Management, Marketing, Financial Forecasting to International Banking. Attempts were 
made to group students together according to their master's degrees to facilitate easier timetabling, but most classes were mixed.

In total, 161 students completed the course. Reasons for attrition might be attributed to timetabling conflicts and increasing workloads on their degree courses. 113 students gave their consent to use their final grades and completed questionnaires. The researcher's relationship with many of the students should be acknowledged as she had taught four classes comprising around $25 \%$ of the cohort. This may have impacted on some of the qualitative data, in terms of a perception of the power imbalance, and perhaps, social desirability bias (King and Bruner, 2000). Strenuous efforts were made to reassure the participants of their anonymity. The timing of the data collection prior to the final assessment may have also had some bearing on student response or non-response. This was unavoidable due to logistical reasons.

\section{Results and Discussion}

Table 1 below shows the results of the respondents, around $70 \%$ of the final cohort.

Table 1. Grades awarded to students who signed consent forms.

\begin{tabular}{|l|l|l|l|l|l|l|l|l|}
\hline $\begin{array}{l}\text { Grade A } \\
\text { (Excellent) }\end{array}$ & $\begin{array}{l}\text { Grade } \\
\text { B } \\
(\text { Very } \\
\text { good })\end{array}$ & $\begin{array}{l}\text { Grade } \\
\text { (Good) }\end{array}$ & $\begin{array}{l}\text { Grade D } \\
\text { (Satisfactory) }\end{array}$ & $\begin{array}{l}\text { Grade } \\
\text { E } \\
\text { (Weak) }\end{array}$ & $\begin{array}{l}\text { Grade } \\
\mathrm{F} \\
\text { (Poor) }\end{array}$ & $\begin{array}{l}\text { Grade } \\
\text { G } \\
(\text { Very } \\
\text { Poor })\end{array}$ & $\begin{array}{l}\text { Credit } \\
\text { Refused }\end{array}$ \\
\hline 13 & 59 & 39 & 2 & & & & & \\
\hline
\end{tabular}

These results suggest that the course in its current configuration is accessible and achievable for most students.

The first two questions gave the students an opportunity to give feedback on the perceived value of the course in terms of employability.

Table 2. Students' perceptions of their progress in writing and employability. 


\begin{tabular}{|l|l|l|l|l|l|l|}
\hline & $\begin{array}{l}\text { strongly } \\
\text { disagree }\end{array}$ & disagree & neutral & agree & $\begin{array}{l}\text { strongly } \\
\text { agree }\end{array}$ & TOTAL \\
\hline $\begin{array}{l}\text { 1. I am more confident } \\
\text { about writing in } \\
\text { professional business } \\
\text { contexts. }\end{array}$ & 4 & 3 & 20 & 74 & 12 & 113 \\
\hline $\begin{array}{l}\text { 2. I am more confident } \\
\text { about applying for jobs } \\
\text { which require the use of } \\
\text { English. }\end{array}$ & 4 & 7 & 32 & 55 & 15 & 113 \\
\hline
\end{tabular}

$76 \%$ of students felt that they were confident about writing in professional business contexts, and $62 \%$ reported that they felt more confident about applying for jobs which require use of English.

The third question was constructed to allow free comment from the students, and as can be seen, the responses were diverse, but with some common emerging themes: Question 3: Are there any improvements that you feel we could make to the course? For 22 questionnaires, question three either had been left blank (12), or the student had answered 'no' to this question (3), or had been very positive (7), for example, 'the course is perfect, it's very good, very helpful, I feel confident'. Following a constructivist grounded theory coding (Mills, Birks and Hoare, 2014), the remaining 91 responses were coded, extracting key words and themes from the participants' comments. In contrast to traditional grounded theory, the constructivist approach regards reality as existing only in relation to a 'specific conceptual scheme, theoretical framework, paradigm, form of life, society or culture' (Bernstein, cited in Mills, Birks and Hoare, 2014, p.109). The researcher's influence on how the questions are worded, and themes are selected and categorised should be acknowledged. In addition, in the constructivist approach, the participant and the researcher are regarded as co-constructing the data (Charmaz and Bryant, 2011). This indeed may be more pertinent than usual as the researcher was known to approximately $25 \%$ of the cohort. Thus, the relationship between the researcher and her own students may be a factor in both the provision and selection of the data. 
Using a framework of initial coding, focused coding, and theoretical coding (Charmaz and Bryant, 2011), the answers to the open-ended questions were scrutinised for key words, and a list was made, recording frequency. In second level coding, focused coding consisted of grouping keywords and related words together. In the theoretical coding stage, a narrative was constructed by the researcher in order to interpret the findings. This third stage, known as theoretical coding by constructivist grounded theorists in addition to traditional grounded theorists, aims to provide 'advanced abstractions that provide a framework for enhancing the explanatory power of your storyline and its potential as theory' (Birks and Mills, 2011, p.123). 'An organised whole theory' (Glaser, 1998, p.163), is produced by 'fracturing the data, and theoretical codes reintegrate these components, weaving the fractured story back together again' (Glaser, 1978, p.72).

\section{Initial coding}

Omitting unique comments, a catalogue of varied and multiple repeated requests was compiled. The most noteworthy word was 'more' in relation to a variety of writing exercises, feedback, formative assessment and help with job applications. Other examples include requests for assistance with essay and proposal writing and more report writing opportunities. There were also requests for help with job applications, internships and suggestions that the course should be a training course.

\section{Focused Coding}

Key words and related words were grouped as follows: feedback, examples, business vocabulary, scenario, writing skills, tasks, speaking, and work experience.

\section{Theoretical coding}

Three distinct categories emerged: an overwhelming request for more of the current course content; requests for additional genre writing; and requests for assistance in genuine employment guidance. It appears that the course has met its stated objectives within the institutional parameters, but that in its present inception, it does not meet the students' perceptions of their needs. Hence, whilst the course can generally be regarded as successful, the data revealed a mismatch between the amount and scope of the current 
content and students' demands. It also has highlighted the lack of connection between traditional Business degrees and the skills necessary to be a successful operator in the workplace.

A very strong message was that students wanted more feedback. This must be balanced with the marking allocation for a ten-credit course. Secondly, there was a resounding demand for more writing practice, more academic writing, more grammar, more vocabulary and more reflective writing. Another request was for a more realistic case study, and a wider range of case studies, for example, a specific case study for Finance students. 'Case study' was interpreted by the researcher to mean scenario. Interestingly, there were also more requests for speaking opportunities, despite there being frequent group discussions. There is also a separate complementary dedicated speaking course. There were also requests for proposal writing and for academic writing such as essays and dissertations. There are several other academic writing support services available. However, specific genre writing courses for Business students such as proposal writing are not currently available and there may be sufficient demand for this to merit further investment and course design. With regard to feedback requesting more help with $\mathrm{CVs}$ and job applications, these are not within the remit of the course. There is an integrated careers service in the Business School, and this may need to be more explicitly signposted to the students.

\section{Conclusion}

It is apparent there is a demand for business communication courses that bridge academia and the workplace. The current course configuration does not meet student needs, rather it seems to have alerted students to the uniqueness of business communication and the disparity between their current language proficiency and this genre. Higher Education Institutions should consider investing in such business communication courses to support their graduates as it appears to be the perception among the students that achieving strong postgraduate degrees from reputable Business schools may not be enough. They are cognisant of the need to acquire workplace communicative proficiency in tandem with academic expertise. Internship programmes may provide authentic opportunities to glean valuable experience, however, these opportunities are rare. Therefore, greater use of scenarios as a learning environment replicating corporate contexts should be considered, 
to complement relevant degree courses. This will have the dual result of equipping the students with necessary skills and enhancing current degree courses. For international Business students, unambiguity, the significance of intertextuality, and appropriate register are of paramount importance on the global stage. Therefore, greater investment in relevant course design may prove beneficial, and increase employability skills and graduate confidence in the workplace.

\section{Acknowledgements}

The researcher would like to thank the course designer for his support, and the anonymous reviewers for their constructive feedback.

\section{References}

Advancing English for Business Writing Course book. (2018-2019) University of Glasgow.

Birks, M. and Mills, J. (2011) Grounded theory: a practical guide. London: Sage publications.

Bremner, S. (2010) 'Collaborative writing: bridging the gap between the textbook and the workplace', English for Specific Purposes, 29, pp.121-132.

Bremner, S. and Costley, T. (2018) 'Bringing reality to the classroom: exercises in intertextuality', English for Specific Purposes, 52, pp.1-12.

Charmaz, K. and Bryant, A. (2011) 'Grounded theory and credibility', in Silverman, D. (ed.) Qualitative research. $3^{\text {rd }}$ edn. London: Sage publications, pp.291-309

Cheng, W. and Cheng, P. (2010) 'Correcting others and self-correction in business and professional discourse and textbooks', in Trosborg A. (ed.) Pragmatics across languages and cultures. Berlin: Mouton de Gruyter, pp.443-466. 
Evans, S. (2013) 'Designing email tasks for the Business English classroom: implications from a study of Hong Kong's key industries', English for Specific Purposes, 31, pp.202-212.

Flowerdew, L. (2010) 'Devising and implementing a business proposal module:

Constraints and compromises'. English for Specific Purposes, 29, pp.108-120.

Glaser, B. G. (1978) Theoretical sensitivity. Mill Valley, CA: Sociology Press.

Glaser, B. G. (1998) Doing grounded theory: issues and discussions. Mill Valley, CA: Sociology Press.

King, M. F. and Bruner, G. C. (2000) 'Social Desirability Bias: A Neglected Aspect of Validity Testing', Psychology and Marketing, 17(2), pp.79-103.

Mills, J., Birks, M., and Hoare, K. (2014) 'Grounded Theory', in Mills, J. and Birks, M. (eds.) Qualitative methodology: a practical guide. London: Sage Publications, pp.107 -122.

Reed, B. (2011) 'Recent Business English publications', ELT Journal, 65(3), pp.326-45.

St John, M. J. (1996) 'Business is booming: Business English in the 1990s'. English for Specific Purposes, 15(1), pp.3-18.

Qi, D.S. and Lapkin, S. (2001). 'Exploring the role of noticing in a three-stage second language writing task', Journal of second language writing, 10(4), pp.277-303

\section{Author details}

Siriol Lewis is a lecturer in English for Academic Study, University of Glasgow. 